\section{Comparison of two esmolol bolus doses on the haemodynamic response and seizure duration during electro- convulsive therapy}

Anthony L. Kovac MD, Hiroshi Goto MD, Manuel P. Pardo MD,* Kasumi Arakawa MD PhD
Twelve ASA physical status I-III patients were enrolled in a double-blind, prospective, randomized, three-way, withinpatient crossover study designed to determine the effect of two standard esmolol bolus doses (100 and $200 \mathrm{mg})$ on the haemodynamic response and seizure duration during electroconvulsive therapy (ECT). Esmolol or placebo was administered one minute prior to induction of anaesthesia and exactly two minutes before ECT. Both the 100 and $200 \mathrm{mg}$ bolus doses significantly blunted the maximum increase in heart rate $(H R)$ and mean arterial pressure (MAP) following ECT in comparison with placebo. Compared with placebo, esmolol $100 \mathrm{mg}$ decreased maximum $H R$ by $23 \pm 3 \%$, maximum MAP by $17 \pm$ $7 \%$ and maximum rate-pressure product (RPP) by $40 \pm 9 \%$. Esmolol $200 \mathrm{mg}$ decreased maximum $H R$ by $25 \pm 3 \%$, maximum MAP by $19 \pm 3 \%$ and maximum RPP by $42 \pm 5 \%$. No significant difference was found between the two esmolol doses at corresponding measurement points before and after ECT. Treatment

\section{Key words}

ANAESTHESIA: electroconvulsive therapy, brain, seizure duration;

COMPLICATIONS: hypertension, tachycardia;

SYMPATHETIC NERVOUS SYSTEM: beta-adrenergic antagonists, esmolol.

From the Departments of Anesthesiology and Psychiatry,* University of Kansas Medical Center, 39th and Rainbow Boulevard, Kansas City, Kansas 66103.

Address correspondence to: Dr. A L Kovac, Department of Anesthesiology, University of Kansas Medical Center, 39th and Rainbow, Kansas City, Kansas 66103.

Presented in part at the 1989 Annual Meeting of the American Society of Anesthesiologists in New Orleans, Louisiana.

Supported by a grant from Dupont Pharmaceuticals. with esmolol $200 \mathrm{mg}$ resulted in a significantly shorter mean seizure duration than with placebo. As the $200 \mathrm{mg}$ dose caused a shorter seizure duration and the haemodynamic effects of 100 $\mathrm{mg}$ and $200 \mathrm{mg}$ doses were similar, it was concluded that the 100 mg esmolol bolus dose was the betler dose for ECT.

Douze patients de classe ASA I-III ont participé à trois séances variées de notre étude randomisée da double insu sur l'effet de deux doses d'esmolol en bolus ( 100 et $200 \mathrm{mg}$ ) sur les variables hémodynamiques et la durée des convulsions associées aux électrochocs (EC). On leur injectait l'esmolol ou un placébo une minute avant l' induction de l'anesthésie puis deux minutes avant l'EC. Comparativement au placébo, les deux doses d'esmolol émoussaient significativement les augmentations maximales de la fréquence cardiaque, de la tension artérielle et dil produit pouls-pression, les réduisant respectivement de $23 \pm 3 \%, 17 \pm$ $7 \%$ et $40 \pm 9 \%$ pour la dose de $100 \mathrm{mg}$ et de $25 \pm 3 \%, 19 \pm 3 \%$ et $42 \pm 5 \%$ pour celle de $200 \mathrm{mg}$. Avant et après l'EC, les valeurs hémodynamiques associées aux deux doses d'esmolol étaient comparables. Toutefois, avec la dose de $200 \mathrm{mg}$, les convulsions duraient significativement moins longtemps qu'avec le placébo. Dans un contexte d'EC. une dose de $100 \mathrm{mg}$ d'esmolol est donc préférable.

Electroconvulsive therapy (ECT) may produce intense stimulation of the central nervous system resulting in hypertension and tachycardia. ${ }^{1,2}$ The haemodynamic effects of ECT could place the patient with coronary or cerebrovascular disease at risk of myocardial ischaemia/ infarction or stroke. ${ }^{3-5}$ Esmolol hydrochloride (Brevibloc) is a new ultra-short acting beta ${ }_{1}$ selective adrenergic blocking agent. Esmolol bolus ${ }^{6}$ and infusion ${ }^{7}$ have been found to be effective in attenuating the cardiovascular response to ECT. However, comparison of the effects of different standardized bolus doses and their effect on the 
TABLE I Exclusion criteria

Pregnant women

Less than 21 yr

AV conduction block greater than $1^{\circ}$

Systolic BP $<100 \mathrm{mmHg}$ or diastolic BP $<50 \mathrm{mmHg}$

Heart rate $<50$ bpm

Bronchospasm or bronchial asthma

Drug allergy or idiosyncracy to beta-adrenergic drugs

Experimental drugs within two weeks

Patients on beta blockers or calcium channel blockers

(i) compare the effect of two standardized esmolol bolus doses (100 and $200 \mathrm{mg}$ ) on heart rate (HR) and blood pressure (BP), and (ii) investigate the effect of these doses on seizure duration during ECT.

\section{Methods}

This study was approved by the Human Subjects Committee of our institution and written informed consent was obtained from each patient. The study patients were ASA physical status I, II, or III and selected from those receiving general anaesthesia for ECT. Exclusion criteria are listed in Table I.

All patients received premedication with glycopyrrolate $0.3 \mathrm{mg}$ im $30-60 \mathrm{~min}$ before ECT. The HR was monitored by ECG, BP by manual cuff, oxygen saturation by pulse oximeter, carbon dioxide by end-tidal $\mathrm{CO}_{2}$ monitor, and seizure duration by EEG. Recording times for $H R$ and BP did not occur during the actual seizure period. All patients received esmolol $100 \mathrm{mg}, 200 \mathrm{mg}$, and placebo (normal saline) in a prospective, randomized, double-blind, three-way, within-patient, crossover design. Thus, each patient served as his or her own control.

Esmolol (or placebo) was administered at time zero by hand-held bolus over $15 \mathrm{sec}$, one minute before induction of anaesthesia and exactly two minutes before ECT. Anaesthesia was induced with methohexitone $1.0 \mathrm{mg} \cdot \mathrm{kg}^{-1}$ and succinylcholine $0.75 \mathrm{mg} \cdot \mathrm{kg}^{-1}$. The $\mathrm{HR}$ and $\mathrm{BP}$ were recorded pre-bolus and every minute for ten minutes post-bolus, then at $12,15,20,25$ and $40 \mathrm{~min}$ following bolus injection. Three to five days later the patients crossed over to the alternative treatment and repeated the procedures outlined above.

A monitored electroconvulsive therapy apparatus (MECTA) machine was used to administer the electrical shock current charge. All ECT shocks were unilateral. All patients received the same electrical shock current for each ECT and received only one shock per treatment (70 $\mathrm{Hz}$, with $1.5 \mathrm{msec}$ pulse width and 2.0 see duration).

\section{Statistical analysis}

Data were evaluated as per cent change from pre-bolus baseline values. All statistical analyses were performed
TABLE II Number of patients receiving concomitant medications

\begin{tabular}{ll}
\hline Medications & Number of patients \\
\hline Levothyroxine & 3 \\
Thioridazine & 3 \\
Ibuprofen & 3 \\
Nortriptyline & 3 \\
Desipramine & 2 \\
Trihexylphenidyl & 2 \\
Triamterene & 2 \\
Haloperidol & 1 \\
Protriptyline & 1 \\
Alprazolam & 1 \\
Fluoxetine & 1 \\
Trazodone & 1 \\
Dipyridamole & 1 \\
Amitriptyline & 1 \\
Imipramine & 1 \\
\hline
\end{tabular}

using the statistical analysis system. ${ }^{8}$ Analysis of variance (in a crossover model) was used to analyze HR, BP, rate-pressure product (RPP) and seizure duration at the successive measurement times. $T$ tests, using the pooled mean square error from the variation among patients within the three treatment groups, were used to determine the relation among the treatments. A $P<0.05$ level was set for statistical significance.

\section{Results}

Of the 12 patients studied, the mean ( \pm SD) age was $52 \pm 19 \mathrm{yr}$ (range 23-78) and mean weight was $70 \pm 13$ $\mathrm{kg}$ (range 54-95). As this was a within-patient comparison, 12 patients were in each study group. Concomitant patient medications are listed in Table II. Medications and/or dosages did not change during the treatment periods. Both the esmolol $100 \mathrm{mg}$ and $200 \mathrm{mg}$ bolus doses were found to blunt significantly the increase in HR (Figure 1), mean arterial pressure (MAP) (Figure 2), and RPP (Figure 3) following ECT in comparison to placebo. HR, MAP, and RPP declined after both esmolol bolus administrations and increased after ECT. Treatment with both esmolol bolus doses resulted in significantly lower maximum per cent changes in HR, MAP, and RPP. There was a significant difference in HR between the $100 \mathrm{mg}$ esmolol dose and placebo for up to four minutes post-ECT and up to $18 \mathrm{~min}$ post-ECT for the $200 \mathrm{mg}$ dose (Figure I). $\mathrm{HR}$ baseline control values (mean $\pm \mathrm{SEM}$ ) for placebo, $100 \mathrm{mg}$, and $200 \mathrm{mg}$ esmolol doses were $85 \pm 5,87 \pm 7$, and $89 \pm 5 \mathrm{bpm}$ respectively. There was a significant difference in MAP between the $100 \mathrm{mg}$ esmolol dose and placebo for up to two minutes post-ECT and up to four minutes post-ECT for the $200 \mathrm{mg}$ dose (Figure 2). MAP baseline control values for placebo, $100 \mathrm{mg}$, and $200 \mathrm{mg}$ esmolol doses were $98 \pm 3,96 \pm 4$, and $105 \pm 4 \mathrm{mmHg}$ 


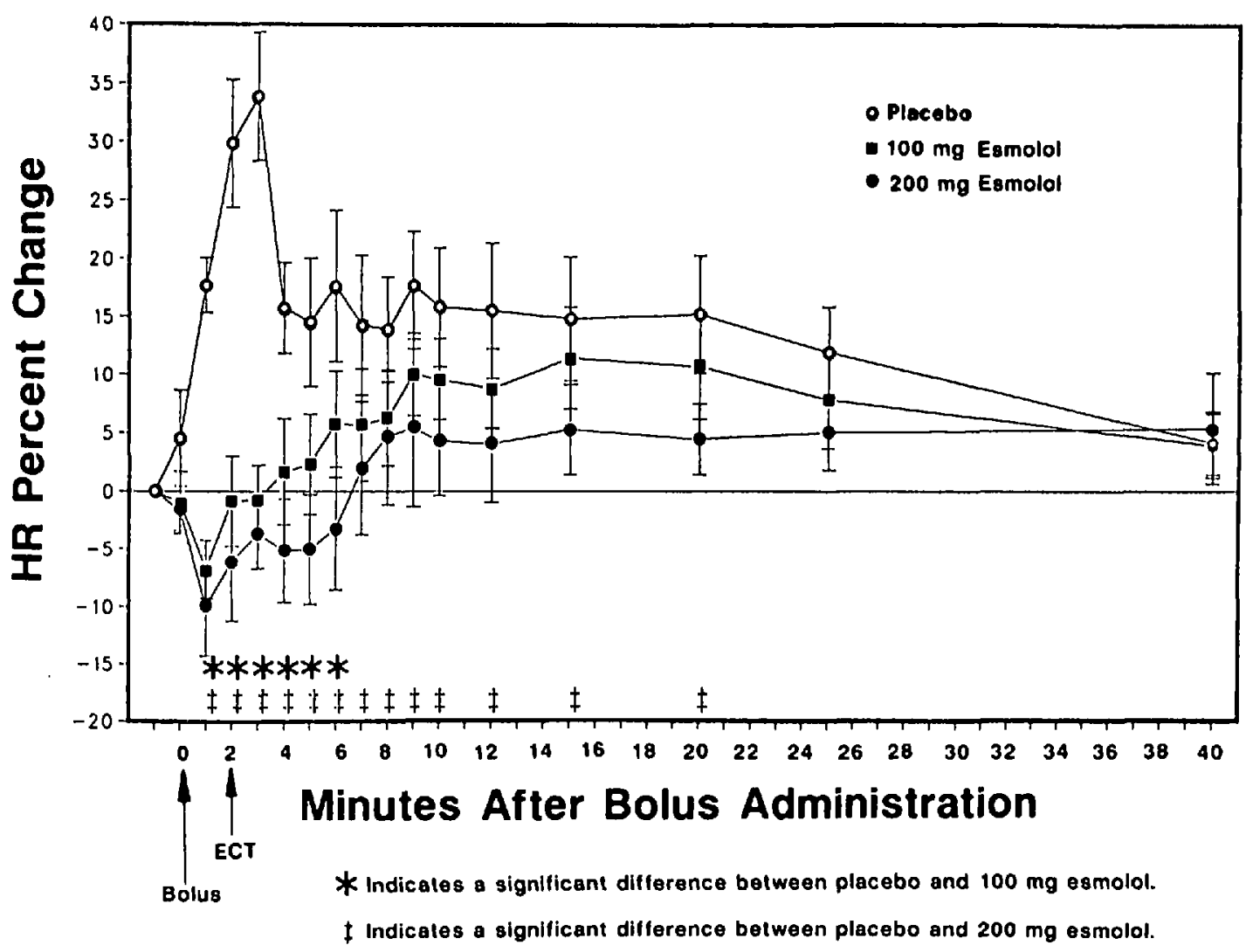

FIGURE I Heart rate per cent change (mean \pm SEM).

respectively. There was a significant difference in RPP between the $100 \mathrm{mg}$ esmolol dose and placebo for up to four minutes post-ECT and up to 13 minutes post-ECT for the $200 \mathrm{mg}$ dose (Figure 3). RPP baseline control values for placebo, $100 \mathrm{mg}$, and $200 \mathrm{mg}$ esmolol doses were $11,000 \pm 600,10,900 \pm 700$, and $12,700 \pm 800$ respectively. Esmolol bolus had a more significant effect on HR than on MAP. There were no significant differences between the two doses with respect to HR, MAP, RPP or seizure duration. However, seizure duration was significantly shorter with $200 \mathrm{mg}$ of esmolol compared with placebo (Table III). No arrhythmias or adverse experiences occurred.

\section{Discussion}

Electroconvulsive therapy is an important modality in the treatment of depression, especially in patients resistant to pharmacological therapy. Electroconvulsive therapy accounts for approximately $4 \%$ of psychiatric admissions in the United States ${ }^{1,9}$ with about 100,000 treatments administered annually. ${ }^{5,10}$

A hyperdynamic cardiovascular response occurs as a result of autonomic nervous system stimulation. Parasympathetic discharge occurs immediately with sympa- thetic discharge following within seconds. Hypertension, tachycardia, and an increase in cardiac output often occur. ${ }^{1,2}$ Although rare, cardiovascular complications are the main cause of death during ECT with a mortality rate of $0.03 \%$ of patients treated, and $0.0045 \%$ of individual ECT treatments. ${ }^{2,5,11}$ This is higher than the often quoted overall anaesthetic mortality of of 1:10,000. ${ }^{12}$ Morbidity and mortality during ECT is usually secondary to myocardial ischaemia/infarction or stroke. ${ }^{2-5}$ Patients who are elderly, have chronic hypertension, or pre-existing cardiac disease are especially at risk for an adverse event occurring in the peri-ECT period. ${ }^{3,4}$

Similar to techniques used for tracheal intubation, many pharmacological methods have been used in at-

TABLE IIl Seizure duration $(n=12)$

\begin{tabular}{ll}
\hline & Seconds \pm SEM \\
\hline Placebo & $52.75 \pm 4.61$ \\
Esmolol $100 \mathrm{mg}$ & $44.58 \pm 4.61$ \\
Esmolol $200 \mathrm{mg}$ & $40.00 \pm 3.09^{*}$ \\
\hline
\end{tabular}

* $P<0.05$ significanl difference between placebo and indicated esmolol bolus dose. 


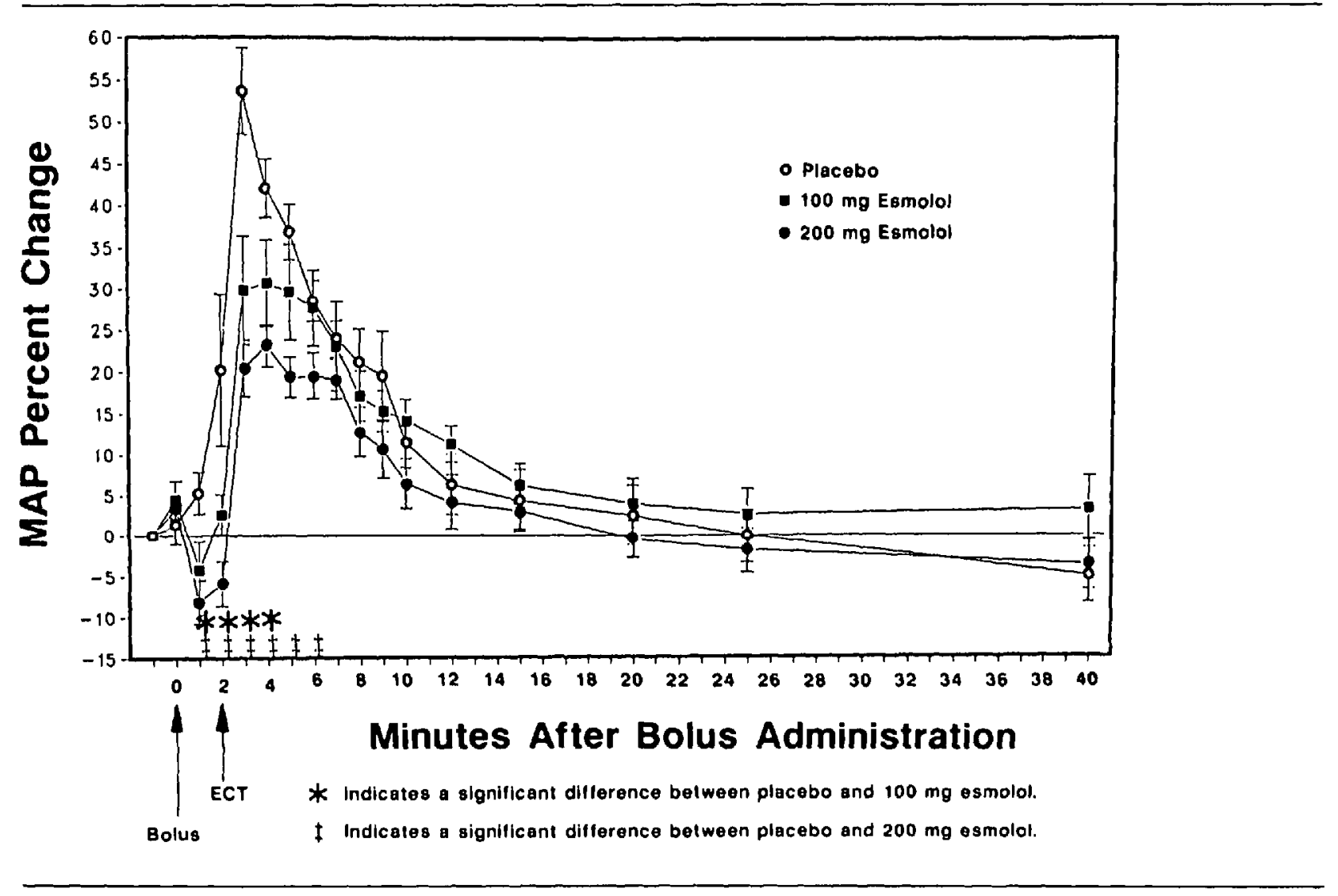

FIGURE 2 Mean arterial pressure per cent change (mean \pm SEM).

tempting to blunt the haemodynamic effects of ECT. These include oral clonidine, ${ }^{13}$ intranasal nifedipine, ${ }^{14}$ nitroglycerin ointment, ${ }^{15}$ iv sodium nitroprusside, ${ }^{13}$ methohexitone, ${ }^{16}$ thiopentone, and propofol, ${ }^{16}$ trimethaphan, ${ }^{17}$ propranolol, ${ }^{18,19}$ hydralazine, ${ }^{19}$ labetalol, ${ }^{20}$ and diazoxide. ${ }^{21}$ Both continous infusion and bolus techniques have been used. Although numerous techniques are available, many have side-effects with durations of action longer than the short ECT stimulus itself.

The ideal agent and/or technique for attenuating the hyperdynamic response of ECT would be convenient, easy to prepare and administer, rapid-acting, brief, non-toxic, and have minimal or no side-efficts. Ideally, duration of action should correspond to the period of time the drug and/or technique is needed.

Esmolol hydrochloride is an ultrashort-acting, beta-one selective blocker with a distribution half-life of two minutes and an elimination half-life of nine minutes. ${ }^{22}$ Esmolol appears quite suitable for use during a short-lived stress such as tracheal intubation or ECT. Administration of esmolol by bolus and infusion has been found to be effective in blunting the haemodynamic effects of laryngoscopy and intubation ${ }^{23}$ as well as intra-operative ${ }^{24}$ and postoperative ${ }^{25}$ stresses.
Previous dosing regimens of esmolol have been confusing and complex. Esmolol originally required dilution of a $2.5 \mathrm{~g}, 10 \mathrm{ml}$ ampule $\left(250 \mathrm{mg} \cdot \mathrm{ml}^{-1}\right.$ in $250 \mathrm{ml}$ of D5W to obtain a $10 \mathrm{mg} \cdot \mathrm{ml}^{-1}$ solution). The manufacturer developed a $100 \mathrm{mg}$ vial $\left(10 \mathrm{mg} \cdot \mathrm{ml}^{-1}\right)$ for convenience and ease of administration. Our selection of 100 and $200 \mathrm{mg}$ bolus doses was selected on this basis (one and two unit vials respectively). A $100 \mathrm{mg}$ and $200 \mathrm{mg}$ dose in a $70 \mathrm{~kg}$ patient corresponds to $1.43 \mathrm{mg} \cdot \mathrm{kg}^{-1}$ and $2.86 \mathrm{mg} \cdot \mathrm{kg}^{-1}$ respectively. Esmolol can effectively be administered as a set dose rather than adjusting for patient weight. ${ }^{22}$ However, if one desires, a $\mathrm{mg} \cdot \mathrm{kg}^{-1}$ dose can also be administered.

Proper bolus timing and dosage in relation to the stimulus is important. The esmolol bolus should be given within two minutes of the expected stimulus ${ }^{26}$ since a bolus dose given three to four minutes before the stimulus may be too early. ${ }^{27}$ We administered esmolol one minute before anaesthesia induction and exactly two minutes before ECT shock. In our experience, esmolol can also be administered immediately after methohexitone and succinylcholine within two minutes before ECT shock and be equally effective.

Comparisons between this bolus study and our previous 


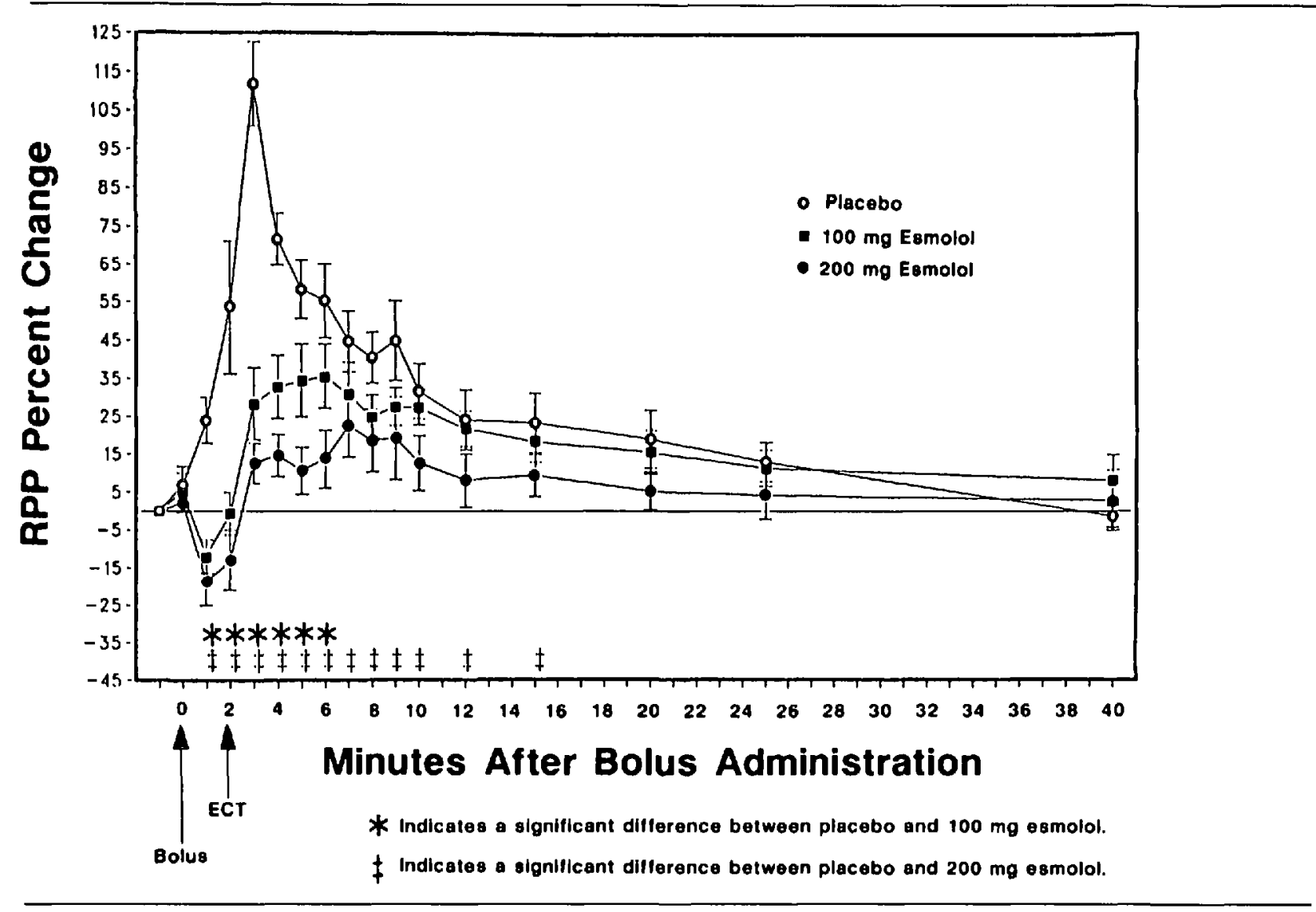

FIGURE 3 Rate-pressure product per cent change (mean \pm SEM).

infusion study ${ }^{7}$ can be made. In the esmolol infusion study, HR renlained below baseline for the entire study. Also, mean MAP increased to $20 \%$ above baseline compared with $43 \%$ in the "no esmolol" group. In this bolus study (Figures I and 2), HR remained below baseline for one and four minutes post-ECT for the 100 $\mathrm{mg}$ and $200 \mathrm{mg}$ esmolol bolus doses respectively. The mean MAP increased to a maximum of $30 \%$ and $23 \%$ above baseline for the $100 \mathrm{mg}$ and $200 \mathrm{mg}$ doses respectively compared with a maximum $54 \%$ increase above baseline for placebo. The increase in MAP was similar for both the bolus and infusion methods.

As seen in Figures $I$ and 2, esmolol's effect is primarily on HR (negative chronotropic effect) and secondarily on BP. This effect was also seen in the esmolol infusion study. The decrease in cardiac output and thus BP is likely secondary not only to decreases in HR but also from decreases in stroke volume secondary to a negative inotropic effect. ${ }^{7}$ The RPP paralleled the course of HR and MAP (Figure 3). While esmolol bolus is more convenient and easier to administer than the infusion method, a more brief control of HR also occurs. Repeat bolus doses may be required post-ECT if further control of
$\mathrm{HR}$ and $\mathrm{BP}$ is desired. Esmolol infusion produces better HR and BP control for a longer time than bolus administration.

The therapeutic effect of ECT depends on a cerebral seizure. There appears to be a dose-response concept to the therapeutic efficacy of ECT with an optimal therapeutic outcome occurring if the seizure lasts approximately $30 \mathrm{sec}$ or longer. ${ }^{28}$ Seizure duration during ECT is influenced by the age and sex of the patient, electrode placement, type of electrical stimulus producing the seizure, blood gas tensions $\left(\mathrm{PO}_{2}\right.$ and $\left.\mathrm{CO}_{2}\right)$, number of treatments already completed, and choice and dose of induction agent. ${ }^{29} \mathrm{~A}$ within-patient crossover design was chosen to eliminate these variables. An end-tidal $\mathrm{CO}_{2}$ monitor was used to keep $\mathrm{CO}_{2}$ approximately 28-30 $\mathrm{mmHg}$ and a pulse oximeter was used to keep oxygen saturation $98-100 \%$.

Esmolol bolus appears to have a dose-related effect on seizure duration (Table III). However, it should also be stressed that for both the 100 and $200 \mathrm{mg}$ bolus doses, seizure durations were longer ( 40 and $45 \mathrm{sec}$, respectively) than the recommended $30 \mathrm{sec}$ minimum.

In summary, both esmolol $100 \mathrm{mg}$ and $200 \mathrm{mg}$ bolus 
doses were found effective in blunting the haemodynamic response during and following ECT in ASA physical status I, II, and III patients. As the $200 \mathrm{mg}$ dose caused a shorter seizure duration and the haemodynamic effects of the 100 and $200 \mathrm{mg}$ doses were similar, the $100 \mathrm{mg}$ esmolol bolus dose was considered to be the better dose for ECT.

\section{References}

I Gaines GY, Rees I. Electroconvulsive therapy and anesthetic considerations. Anesth Analg 1986; 65: 1345-56.

2 Selvin BL. Electroconvulsive therapy - 1987. Anesthesiology 1987; 67: 367-85.

3 Gerring $J$, Shields $H$. The identification and management of patients with a high risk for cardiac arrhythmias during modified ECT. J Clin Psychiatry 1982; 43: 140-3.

4 Alexopoulos GS, Shamoian CJ, Lucas J, Weiser N, Berger $\boldsymbol{H}$. Medical problems of geriatric psychiatric patients and younger controls during electroconvulsive therapy. J Am Geriatr Soc 1984; 32: 65I-4.

5 Knos $G B$, Sung $Y F$, Cooper $R C$, Stoudemire A. Electroconvulsive therapy induced hemodynamic changes unmask unsuspected coronary artery disease. Journal of Clinical Anesthesia 1990; 2: 37-41.

6 Klein $M$, Martin $O$, Soloff $P$, Dealy RS, Ghignone $M$. Comparison of the effect of nitroglycerin and esmolol on the cardiovascular response to ECT. Anesthesiology 1988; 69: A41.

7 Kovac AL, Goto H, Arakawa K, Pardo MP. Esmolol bolus and infusion attenuates increases in blood pressure and heart rate during electroconvulsive therapy. Can J Anaesth 1990; 37: 58-62.

8 SAS Institute Inc. SAS users' guide: statistics, 1982 edition. Cary, NC: SAS Institute Inc, 1982: 113.

9 Asnis G, Fink M, Saferstein S. ECT in metropolitan New York hospitals. Am J Psychiatry 1978; 135: 479-82.

10 Holden $C$. A guarded endorsement for electroshock therapy. Science 1985; 228: 1510-1.

11 The Royal College of Psychiatrists' memorandum on the use of electroconvulsive therapy. $\mathrm{Br}$ J Psychiatry 1977; 131: 261-72.

12 Tinker J, Roberts S. Anesthesia risk. In: Miller R (Ed.). Anesthesia Vol. 1. 2nd ed. New York. Churchill Livingston. 1986: 368.

13 Liu WS, Petty WC, Jeppsen A, Wade EJ, Pace NL. Attenuation of hemodynamic and hormonal responses to ECT with propranolol, xylocaine, sodium nitroprusside or clonidine. Anesth Analg 1984; 63: 244.

14 Kalayam B, Alexopoulos GS. Nifedipine in the treatment of blood pressure rise after ECT. Convulsive Therapy 1989; 5: 110-3.
15 Lee JT, Erbguth PH, Stevens WC, Sack RL. Modification of electroconvulsive therapy induced hypertension with nitroglycerin ointment. Anesthesiology 1985; 62: 793-6

16 Rampton AJ, Griffin RM, Stuart CS, Durcan JJ, Huddy $N C, A b b o t t M A$. Comparison of methohexital and propofol for electroconvulsive therapy: effects on hemodynamic response and seizure duration. Anesthesiology 1989; 70: 412-7.

17 Regenstein $Q R$, Lind $L$. Management of electroconvulsive treatment in an elderly woman with severe hypertension and cardiac arrhythmias. Compr Psychiatry 1980; $21: 288-91$.

18 Jones RM, Knight PR. Cardiovascular and hormonal responses to electroconvulsive therapy: modification of an exaggerated response in a hypertensive patient by B-receptor blockade. Anaesthesia 1981; 36: 795-9.

19 Husum B, Vester-Anderson T, Buchmann G, Bolwig $T G$. Electroconvulsive therapy and intracranial aneurysm. Prevention of blood pressure elevation in a normotensive patient by hydralazine and propranolol. Anaesthesia 1983; 38: 1205-7.

20 Knos $G B$, Sung YF, Stoudemire A, Gladson $M$, Cooper $R$, Markwalter $H$. Use of labetalol to control cardiovascular responses to electroconvulsive therapy. Anesth Analg 1990; 70: S210.

21 Kraus RP, Remick RA. Diazoxide in the management of severe hypertension after electroconvulsive therapy. Am J Psychiatry 1982; 139: 504-5.

22 Sintetos AL, Hulse J, Pritchett ELC. Pharmacokinetics and pharmacodynamics of esmolol administered as an intravenous bolus. Clin Pharmcol Ther 1987; 41: 112-7.

23 Sheppard S, Eagle CJ, Strunin L. A bolus dose of esmolol attenuates tachycardia and hypertension after tracheal intubation. Can J Anaesth 1990; 37: 202-5.

24 Oxorn D, Knox JWD, Hill J. Bolus doses of esmolol for the prevention of perioperative hypertension and tachycardia. Can J Anaesth 1990; 37: 206-9.

25 Gibson BE, Oliver SB, Maass L, Cucchiara RF. Esmolol for the control of hypertension following neurologic surgery. Anesth Analg 1988; 67: S71.

26 Jacque JJ, Gold MI, Grosnoff D, Whirley J, Herrington C. Does single bolus esmolol 2 minutes before intubation prevent tachycardia? Anesth Analg 1989; 68: SI33.

27 Jacque JJ, Grosnoff DB, Whirley J, Gold MI, Herrington $C A$. Esmolol bolus before anesthetic induction for tachycardia-hypertension. Anesth Analg 1989: 68: S134.

$28 O^{\prime}$ Connell RA. A review of the use of electroconvulsive therapy. Hosp Comm Psychiatry 1982; 33: 469-73.

29 Sackeim H, Decima P, Prohovnik I, Malitz S. Seizure threshold in electroconvulsive therapy. Arch Gen Psychiatry 1987: 44: 355-60. 